\title{
First Operation of a Step-Frequency Tunable 1MW Gyrotron with a Diamond Brewster Angle Output Window
}

\author{
G. Gantenbein, A. Samartsev, G. Aiello, G. Dammertz, J. Jelonnek, Member, IEEE, M. Losert, \\ A. Schlaich, Student Member, IEEE, T. Scherer, D. Strauss, M. Thumm, Fellow, IEEE, and \\ D. Wagner, Member, IEEE
}

\begin{abstract}
Experimental results using a step-frequency tunable D-band gyrotron are reported. The short-pulse ( $3 \mathrm{~ms})$ gyrotron is equipped with an elliptically brazed CVD diamond Brewster angle output window. It is designed for the operation in the frequency range from $111.6 \mathrm{GHz}$ up to $165,7 \mathrm{GHz}$. Operating parameters for 10 different frequencies corresponding to an equal number of different cavity operating modes has been measured. A minimum output power of $830 \mathrm{~kW}$ and a peak output power of $1.3 \mathrm{MW}$ have been realized. For all frequencies the parameters of the RF beam generated by the internal quasioptical converter, such as fundamental Gaussian contents and beam waist, are sufficiently good to allow an efficient coupling of the RF power out of the window.

This is the first time a diamond Brewster angle window has been used in a high power gyrotron ( $1 \mathrm{MW})$. Such a system offers the path to a simple and compact window solution for high power broadband applications using gyrotrons.
\end{abstract}

Index Terms-Fusion, Plasma heating, Gyrotron, Output window, Brewster angle, CVD diamond, Frequency tunability

\section{INTRODUCTION}

In recent years electron cyclotron resonance heating and $\mathbf{I}_{\text {current drive (ECRH and ECCD) has been established as a }}$ successful instrument for magnetically confined fusion plasmas. Gyrotrons are the unique sources which meet the

Manuscript received .

This work, supported by the European Communities under the contract of Association between EURATOM and KIT, was carried out within the framework of the European Fusion Development Agreement. The views and opinions expressed herein do not necessarily reflect those of the European Commission.

G. Gantenbein, A. Samartsev, G. Dammertz, J. Jelonnek, M. Losert, A. Schlaich and M. Thumm are with the Karlsruhe Institute of Technology (KIT), Institute for Pulsed Power and Microwave Technology (IHM), Association EURATOM-KIT, Kaiserstrasse 12, 76131 Karlsruhe, Germany (phone: +49 721608 22465; fax: +49 721608 24874; e-mail: gerd.gantenbein@kit.edu).

G. Aiello, T. Scherer and D. Strauss are with the Karlsruhe Institute of Technology (KIT), Institute for Applied Materials (IAW-AWP), Association EURATOM-KIT, Kaiserstrasse 12, 76131 Karlsruhe, Germany.

A. Schlaich is also with the Karlsruhe Institute of Technology (KIT), Institut für Hochfrequenztechnik und Elektronik (IHE), Kaiserstrasse 12, 76131 Karlsruhe, Germany.

D. Wagner is with the Max-Planck-Institut fuer Plasmaphysik, Association EURATOM-IPP, Boltzmannstrasse 2, 85748 Garching . extraordinary requirements of those applications: RF output power in the MW range, operating frequencies at about $100-$ $200 \mathrm{GHz}$, and pulse lengths of several seconds up to continuous wave (CW). Due to its excellent coupling to the plasma and the very good localization of the absorbed RF power, ECRH is applied in present day machines and is also foreseen in all large forthcoming fusion projects: it will be the main heating system for the W7-X stellarator and it will also be employed at the tokamaks ITER and JT-60SA which are currently under construction and it will play a major role in a future DEMO power plant.

In particular advanced tokamaks are operated in a plasma regime where magneto-hydrodynamic instabilities, occurring at different locations in the plasma, may limit the performance. To a large extent the stability in a tokamak is influenced by the distribution of the internal plasma currents which can be manipulated by the injection of RF waves. These effects call for very localized current drive. The location of the absorption of RF waves with the angular frequency $\omega$ is dependent on the resonance condition $\omega-\mathrm{k}_{\mathrm{z}} \mathrm{v}_{\mathrm{z}}=\omega_{\mathrm{c}}\left(\mathrm{k}_{\mathrm{z}}: \mathrm{z}\right.$ component of the wave number, $\mathrm{v}_{\mathrm{z}}$ : electron velocity along $\mathrm{z}-$ axis). The cyclotron frequency $\omega_{c}$ of electrons is proportional to the magnetic induction $\mathrm{B}$. Since in a tokamak the magnetic field $\mathrm{B}(\mathrm{R})$ is monotonically decreasing with increasing major radius $R$, the deposition center is a unique function of the wave frequency for radial injection. Thus, by changing the RF frequency $\omega$ the absorption can be moved to any radial position where the local cyclotron frequency of the electrons $\omega_{\mathrm{c}}$ holds for the expression above [1]. This concept avoids any mechanically moveable components close to the plasma in a harsh environment.

Today, high power gyrotrons for fusion applications in the relevant frequency range with an output power of about $1 \mathrm{MW}$ operate at a fixed frequency. In some cases gyrotrons are designed for two or more discrete frequencies with a separation of a few tens of $\mathrm{GHz}$ taking benefit of a minimum of reflection at the single disk output window if the thickness of the disk correspond to an integer multiple of half of the wavelength of the RF radiation in the material (see e.g. [2, 3, 4]). Frequency step-tunable gyrotrons (beyond the dual frequency range) are not standard products since these broadband tubes require additional optimization of the key 
components, namely the electron beam forming optics, interaction cavity, quasi-optical mode converter and output window $[5,6]$.

The design of the output window of a frequency step-tunable gyrotron is a particular challenge since it has to provide operation of the gyrotron at different frequencies with minimum reflection of the RF waves. From a technological point of view the design and material must support reliable CW operation with low RF losses in and adequate cooling of the disk. Due to its very good mechanical and electrical properties chemical vapor deposition (CVD) diamond has been established in recent years as a standard material for output window disks of high power $\mathrm{CW}$ tubes [7]. In the literature several different approaches of broadband window types such as circularly brazed Brewster diamond window with specific beam optics [3], double disk windows [8] and "travelling wave" windows [9] are reported. From a physics point of view a Brewster angle window with straight transmission without additional beam optics is the most elegant solution since it needs only one diamond disk. It is characterized by a simple and compact unit. For the geometry of Ref. [3] the metallic reflector close to the air side of the diamond disk may lead to arcing induced by the strongly focused RF beam. Therefore, in this publication we report on results with an elliptically brazed diamond disk.

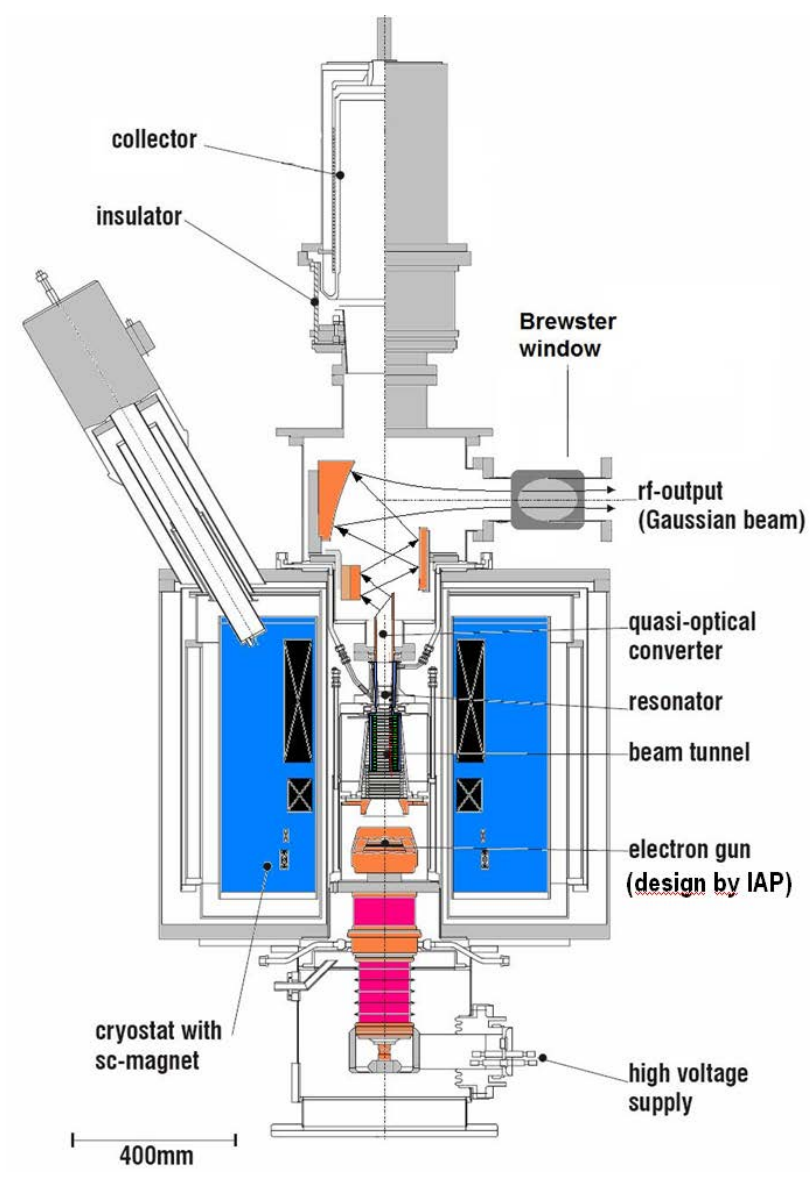

Fig. 1: Modular design of the step-frequency tunable D-band gyrotron with quasi-optical mode converter and lateral RF output with a Brewster angle window.
The gyrotron and the experimental set-up is described in chapter II, the most important features of the diamond disk are given in chapter III. Chapter IV reports on low power RF measurements which have been performed with the Brewster angle window. In chapter $\mathrm{V}$ the results of gyrotron operation is discussed.

\section{EXPERIMENTAL SET_UP}

The experimental investigations were performed with the modular step-frequency tunable short pulse ( $\sim \mathrm{ms})$ D-band gyrotron at KIT [10] which is schematically shown in Figure 1. Originally this device has been designed for the $\mathrm{TE}_{22,6}$ mode operation at $140 \mathrm{GHz}$ [11]. It was the first high power gyrotron operated with a Brewster angle window which in the early phase consisted of a fused silica quartz glass or SiN disk. A combination of the super conducting magnet system and a normal conducting coil system has been used to demonstrate fast ( $1 \mathrm{~s}$ ) step-frequency tuning in the frequency range from $132 \mathrm{GHz}$ up to $147 \mathrm{GHz}$ [12]. In 2002 the operating cavity mode of the tube has been modified [13] in order to be compatible with a parallel development in cooperation with the Institute of Applied Physics, Nizhny Novgorod, Russia.

This gyrotron has the advantage of being modular and allows the relative simple replacement of all key components. Furthermore, it is designed for broadband operation with regard to all components such that experiments over a wide parameter range can be performed.

The step-frequency tunable gyrotron was designed for operation in the frequency range $105-143 \mathrm{GHz}$ in different operating modes (e.g. $\mathrm{TE}_{17,6}$ at $105 \mathrm{GHz}, \mathrm{TE}_{20,7}$ at $124 \mathrm{GHz}$, $\mathrm{TE}_{22,7}$ at $131 \mathrm{GHz}$ and $\mathrm{TE}_{22,8}$ at $140 \mathrm{GHz}$ ) [13]. Frequencystep tuning is performed by changing the magnetic field and exciting corresponding TE modes in the cavity, while at a fixed magnetic field mainly the acceleration voltage is changed, yielding different RF output power levels. Typical high power operating parameters of the gyrotron are an accelerating voltage of $80 \mathrm{kV}$ and a beam current of $40 \mathrm{~A}$. However, beam currents up to $50 \mathrm{~A}$ have been used in the experiments. Details of the gyrotron can be found in [14]. The electron gun is a diode type magnetron injection gun which was designed and manufactured by the Institute of Applied Physics (IAP), Nizhny Novgorod, Russia [15]. Some of the most important design parameters are given in Table I.

Table I: Design parameters of step-frequency tunable gyrotron

\begin{tabular}{|l|r|}
\hline Cavity mode at $140 \mathrm{GHz}$ & $\mathrm{TE}_{22,8}$ \\
\hline Output power [MW] & 1 \\
\hline Accelerating voltage [kV] & 80 \\
\hline Beam current [A] & 40 \\
\hline Velocity ratio at cavity, $\mathrm{v}_{\perp} / \mathrm{v}_{\|}$ & 1.4 \\
\hline Magnetic induction at cavity [T] & 5.54 \\
\hline Frequency range [GHz] & $105-143$ \\
\hline Pulse length [ms] & $<10$ \\
\hline
\end{tabular}



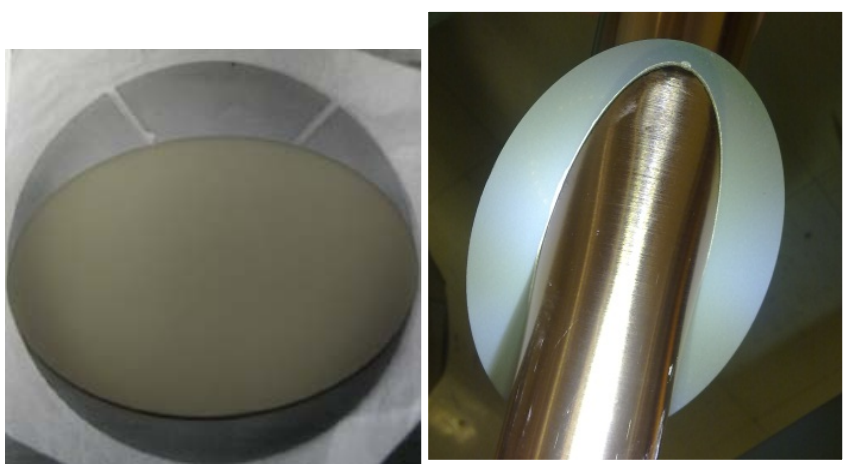

Fig. 2: Diamond disk laser cut from circular disk (left) and brazed to copper cuffs (right).

\section{DESIGN OF BREWSTER ANGLE WINDOW}

In order to minimize reflection of a linearly polarized beam at any frequency at the interface of a material with refractive index $\mathrm{n}_{1}$ and a material with refractive index $\mathrm{n}_{2}$ the input angle must be $\Theta_{\mathrm{B}}=\arctan \left(\mathrm{n}_{2} / \mathrm{n}_{1}\right)$ (Brewster angle) and the polarization vector must be in the reflection plane. Taking a dielectric constant $\varepsilon_{\mathrm{r}}=5.67$ for diamond results in a Brewster angle of $67.2^{\circ}$. Simple calculations using analytic formulae predict reflections below $-30 \mathrm{~dB}$ for a variation of $\Theta_{\mathrm{B}}$ in the order of $\pm 1.5^{\circ}$. The dimensions of the elliptically shaped diamond disk which was laser cut from a circular disk are: 139 x 95 x $1.7 \mathrm{~mm}$ (see Fig. 2).

The brazing of the disk was performed in cooperation with the company Thales Electron Devices, Velizy-Villacoublay, France. Several brazing tests have been performed with dummy ceramic disks in order to optimize the brazing tool. Finally, the diamond disk is brazed with an Ag based brazing material to cylindrical copper cuffs which have an outer diameter of $50 \mathrm{~mm}$, the inner diameter of the system is $49 \mathrm{~mm}$ and the total length of the unit is $206 \mathrm{~mm}$. This system is integrated into a housing which is flanged to the gyrotron. Since the pulse length of the gyrotron is limited to a few ms no cooling of the window unit is foreseen.

Structural analyses based on static finite element (FEM) simulations have been performed in order to check the stresses in the device after the cool down phase of the brazing process (see Fig. 3). In fact, the process is carried out in vacuum at $800^{\circ} \mathrm{C}$ and, since copper and diamond have very different thermal expansion coefficients (ratio of 16 to 1 at $20^{\circ} \mathrm{C}$, respectively), the cool down phase to room temperature results in high stresses that might lead to failure of the disk. Stresses and deformations were calculated by decreasing the temperature from $800^{\circ} \mathrm{C}$ down to $20^{\circ} \mathrm{C}$. For the analysis of stresses in the brittle diamond the first principal stress was used while for the ductile copper the equivalent (von Mises) stress was calculated. The first principal stress is in the range of $30 \mathrm{MPa}-75 \mathrm{MPa}$ along the contact region between the disk and the cuffs and reaches a maximum level of $137.4 \mathrm{MPa}$ at the tip of the disk in the contact region with the longer side of
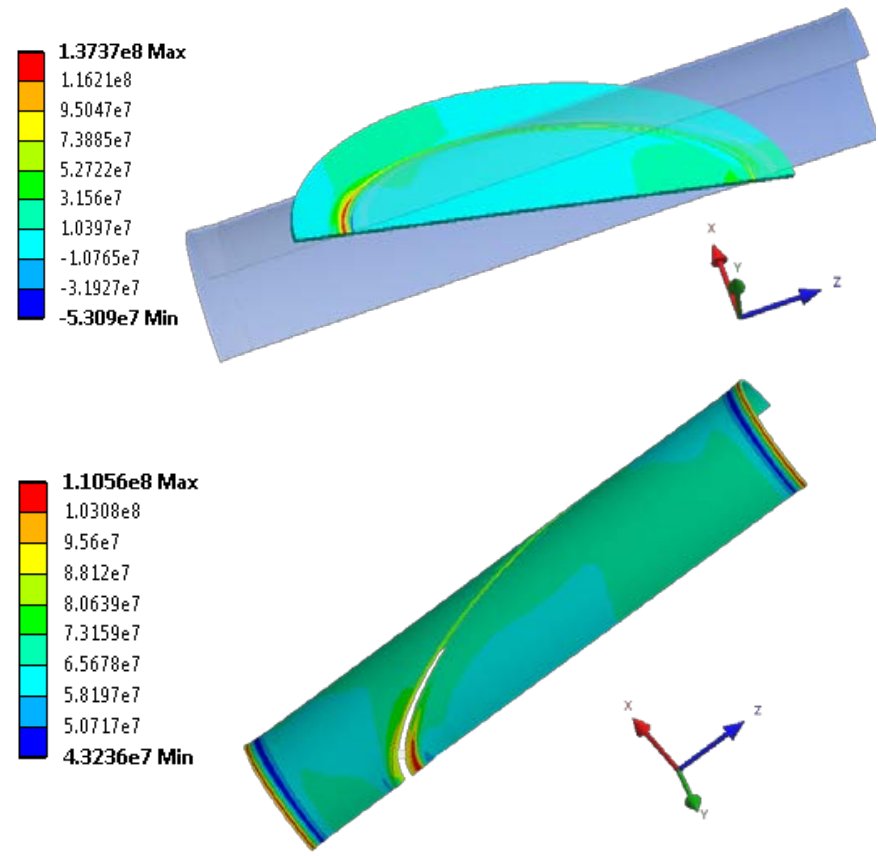

Fig. 3: First principal stress distribution on the top side of the diamond disk (top) and averaged von Mises stress for the copper cuffs (values are in $\mathrm{Pa}$ ).

the cuffs. This corresponds to an increase factor of 1.4 compared to a circular disk.

The cuffs experience plastic behavior, in fact the equivalent stress varies between 50 and $75 \mathrm{MPa}$ (yield strength of OFHC copper is $45 \mathrm{MPa}$ at $20^{\circ} \mathrm{C}$ ) in the most part of the cuffs and has maximum values in the range 103.1-110.6 MPa, located

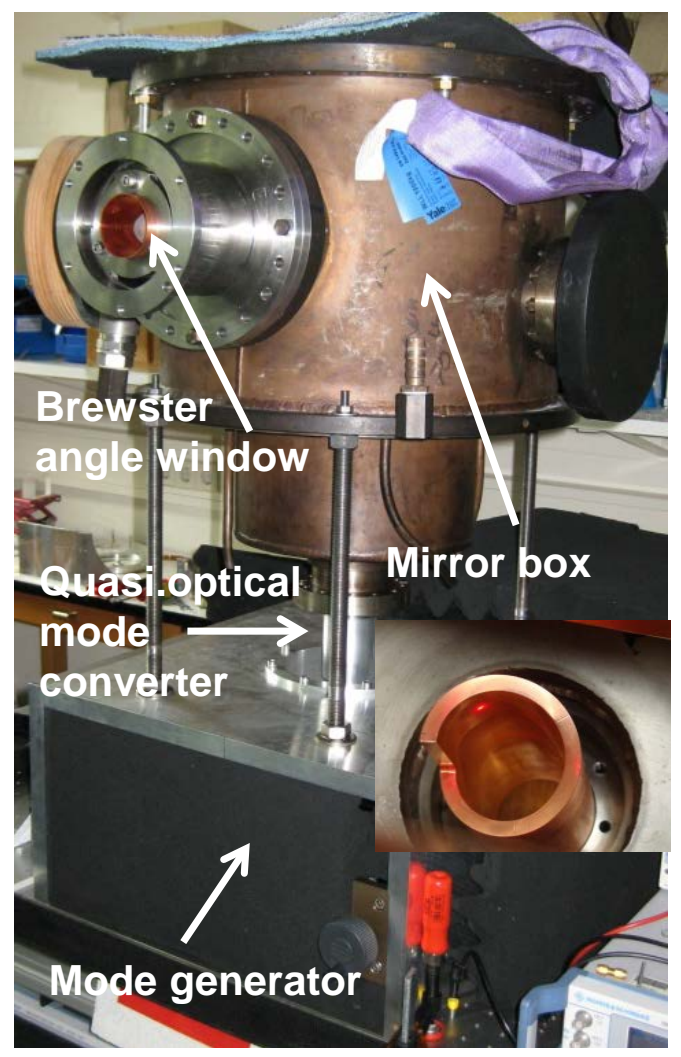

Fig. 4: Experimental setup for low power measurements and built-in quasioptical mode converter. 
close to the area of maximum principal stress and to the support. However, the maximum first principal stress is below the permissible stress of diamond which is $150 \mathrm{MPa}$ (ultimate strength is approximately 450MPa [16]) and the maximum equivalent stress is below the ultimate strength of OFHC copper $\left(250 \mathrm{MPa}\right.$ at $\left.20^{\circ} \mathrm{C}\right)$.

\section{LOW POWER MEASUREMENTS WITH DIAMOND BREWSTER ANGLE WINDOW}

In order to verify the RF performance of the complete quasi-optical system including the window, low power RF measurements have been performed prior to installation into the gyrotron. A mode generator, optimized for the $\mathrm{TE}_{22,8}$ mode at $140 \mathrm{GHz}$, has been used to test the quasi-optical mode converter and the 3-mirror system. The mode generator as well as the measurement technique are discussed in more detail in [17]. The experimental set-up for the low power RF measurements are shown in Fig. 4.

According to the design the beam waist of the Gaussian output beam is targeted for $\mathrm{w}_{0} \sim 12 \mathrm{~mm}$, centered at the position of the disk with a small variation for the different modes and frequencies. Fig. 5 shows the measured output wave beam of the generated $\mathrm{TE}_{22,8}$ mode at a distance of about $518 \mathrm{~mm}$ from the center of the window. It is assumed that small distortions from a perfect Gaussian beam which are
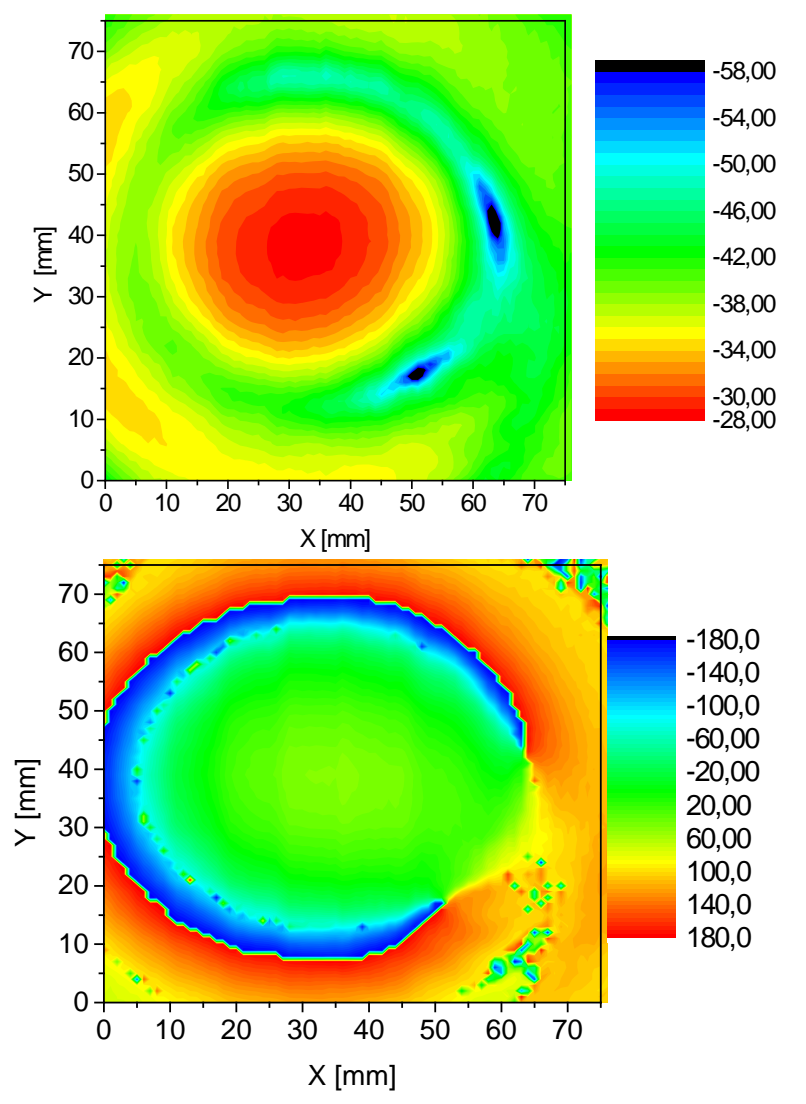

Fig. 5: Low power RF measurement of amplitude (top, values in $\mathrm{dB}$ ) and phase (bottom, values in deg) of Gaussian output beam at $140 \mathrm{GHz}$ (518 mm from center of window). visible in the amplitude and phase are caused by a non-ideal generation of the $\mathrm{TE}_{22,8}$ mode, non-perfect quasi-optical launcher or diffraction (e.g. at the limited aperture of the window unit). A numerical analysis is applied to the complex field pattern. It maximizes the overlap of a $\mathrm{TEM}_{00}$ mode with the measured profile and analyses the remaining field in terms of higher $\mathrm{TEM}_{\mathrm{mn}}$ mode contributions taking 13 x 13 modes into account. The analysis of the profile at $518 \mathrm{~mm}$ and a profile measured at about $203 \mathrm{~mm}$ from the center of the window in terms of Gaussian mode content shows consistently a $\mathrm{TEM}_{00}$ mode content of $95 \%$. The RF power transmission through the window aperture is estimated to be higher than 99.5\%.

\section{STEP-TUNABLE OPERATION OF GYROTRON WITH BREWSTER ANGLE WINDOW}

During the experimental investigations reported here the gyrotron has been operated in up to 10 different modes covering the frequency range from $111.6 \mathrm{GHz}$ up to 165.7 GHz (see Table II). The output beam of each mode has been recorded using infrared measurements of the thermal beam pattern on a suitable target at different positions along beam propagation. Thus it is possible to reconstruct the complex field structure using appropriate algorithms (see e.g. [18]). As an illustration of the beam profile Fig. 6 shows the measured beam pattern of the modes $\mathrm{TE}_{20,7}(124.1 \mathrm{GHz}), \mathrm{TE}_{22,8}(140.0$ $\mathrm{GHz})$, and $\mathrm{TE}_{23,8}(143.3 \mathrm{GHz})$. The pictures have been taken at $760 \mathrm{~mm}$ distance from the center of the window disk, showing an area with a cross section of $80 \times 80 \mathrm{~mm}$. With respect to the position of the $\mathrm{TE}_{22,8}$ mode the center of the mode $\mathrm{TE}_{20,7}$ is shifted approximately by $-5.9 /-1.3 \mathrm{~mm}$ and the mode $\mathrm{TE}_{23,8}$ by $-0.6 / 1.0 \mathrm{~mm}$ which is much less than the aforementioned $1.5^{\circ}$.

Table II: Gaussian mode content according to experiment and simulation

\begin{tabular}{|c|c|c|c|}
\hline Mode & $\begin{array}{c}\text { Frequency } \\
{[\mathrm{GHz}]}\end{array}$ & $\begin{array}{c}\mathrm{TEM}_{00}[\%] \\
\text { Experiment }\end{array}$ & $\begin{array}{c}\mathrm{TEM}_{00}[\%] \\
\text { Simulation }\end{array}$ \\
\hline $\mathrm{TE}_{19,6}$ & 111.6 & 89.5 & 90.4 \\
\hline $\mathrm{TE}_{20,7}$ & 124.1 & 92.1 & 93.4 \\
\hline $\mathrm{TE}_{21,7}$ & 127.5 & 93.5 & 91.7 \\
\hline $\mathrm{TE}_{21,8}$ & 137.0 & 92.8 & 93.0 \\
\hline $\mathrm{TE}_{22,8}$ & 140.0 & 94.0 & 93.3 \\
\hline $\mathrm{TE}_{23,8}$ & 143.3 & 92.4 & 91.5 \\
\hline $\mathrm{TE}_{24,9}$ & 155.8 & 85.0 & Not \\
\cline { 1 - 3 } $\mathrm{TE}_{25,9}$ & 159.2 & 91.0 & \multirow{2}{*}{ investigated } \\
\cline { 1 - 2 } $\mathrm{TE}_{26,9}$ & 162.4 & 92.4 & \\
\cline { 1 - 2 } $\mathrm{TE}_{27,9}$ & 165.7 & 92.8 & \\
\cline { 1 - 2 } & \multicolumn{2}{|r}{} \\
\hline
\end{tabular}




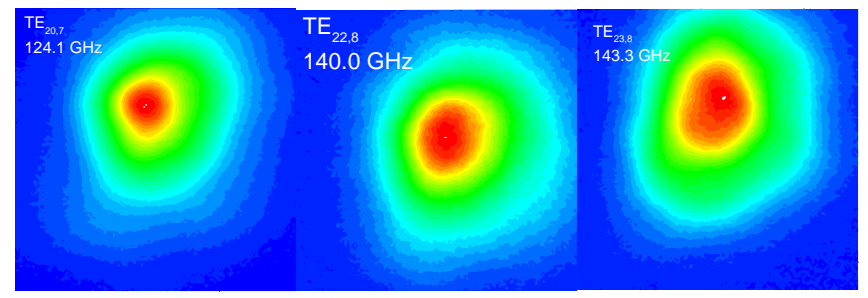

Fig. 6: Output beam profiles measured with an IR system at several frequencies.

The experimental results and a comparison with simulations are given in Table II. Note that the launcher has been designed according to [19] which is a broadband design taking modes into account up to the $\mathrm{TE}_{23,8}$ at $143.3 \mathrm{GHz}$. In general there is a very good agreement of the results (low power RF measurements, high power measurements and simulations), small deviations arise from the limited accuracy of the measurement technique and the numerical stability of the analysis procedure. Nevertheless, it should be mentioned that the design shows in the experiment also a high fundamental Gaussian mode content for higher order operating modes which have not been considered initially in the design phase. In order to reduce stray radiation and minimize thermal loading of the transmission components the $\mathrm{TEM}_{00}$ mode content should be as high as possible, for single frequency gyrotrons this part is usually $>95 \%$.

Optimization and high power experiments have been performed for modes in the frequency range from $124.1 \mathrm{GHz}$ up to $162.5 \mathrm{GHz}$. The gyrotron has been operated in the $1 \mathrm{MW}$ power regime for all operating modes. A maximum peak power of 1.3 MW in short-pulse operation has been achieved at $143.3 \mathrm{GHz}$ and at a beam current of $52 \mathrm{~A}$. Fig. 7 shows the achieved output power versus the beam current for the $\mathrm{TE}_{23,8}$ mode and an optimized magnetic field. That measurement demonstrates that the operation of the $\mathrm{TE}_{23,8}$ mode is stable over a broad beam current range from $10 \mathrm{~A}$ to $52 \mathrm{~A}$ with a corresponding output power from $100 \mathrm{~kW}$ up to $1.3 \mathrm{MW}$. The gyrotron has been operated in the short pulse regime $(\sim 3 \mathrm{~ms})$ without depressed collector. The output power has been

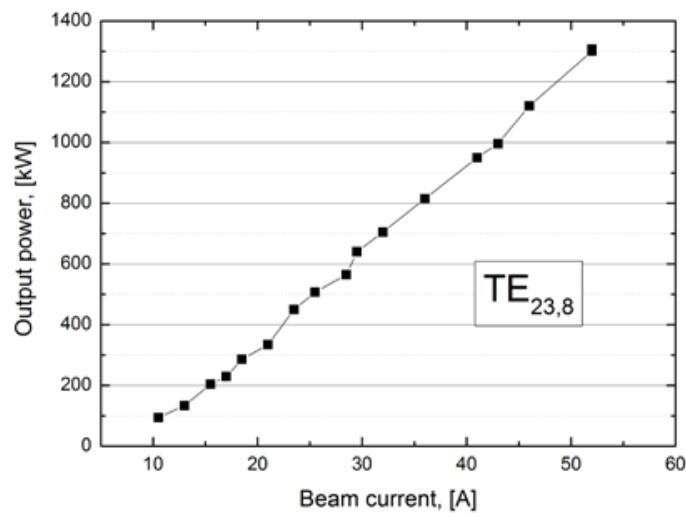

Fig. 7: Gyrotron output power versus beam current for the $\mathrm{TE}_{23,8}$ mode.
Table III: Output power of the different modes.

\begin{tabular}{|l|l|l|l|l|l|}
\hline Mode & $\begin{array}{l}\text { Frequency } \\
{[\mathrm{GHz}]}\end{array}$ & $\begin{array}{l}\mathrm{U}_{\text {cath }} \\
{[\mathrm{kV}]}\end{array}$ & $\begin{array}{l}\mathrm{I}_{\text {beam }} \\
{[\mathrm{A}]}\end{array}$ & $\begin{array}{l}\text { Power } \\
{[\mathrm{kW}]}\end{array}$ & $\begin{array}{l}\text { Efficiency } \\
{[\%]}\end{array}$ \\
\hline $\mathrm{TE}_{20,7}$ & 124.1 & 91.7 & 42 & 900 & 23.4 \\
\hline $\mathrm{TE}_{21,7}$ & 127.4 & 90.0 & 42 & 920 & 24.3 \\
\hline $\mathrm{TE}_{22,8}$ & 140.0 & 91.0 & 50 & 1250 & 27.5 \\
\hline $\mathrm{TE}_{23,8}$ & 143.3 & 92.9 & 52 & 1300 & 26.9 \\
\hline $\mathrm{TE}_{25,9}$ & 159.2 & 92.3 & 40 & 975 & 26.4 \\
\hline $\mathrm{TE}_{26.9}$ & 162.5 & 92.3 & 41 & 950 & 25.1 \\
\hline
\end{tabular}

measured with a precise short pulse calorimeter which was directly placed at the output window flange. A summary of the results for other operating modes in terms of output power and efficiency is given in Table III. Note that the efficiency is calculated using the cathode voltage. This does not take into account voltage depression due to the electron beam and thus a reduced electron energy during the start-up phase.

\section{CONCLUSIONS}

For the first time an elliptically brazed Brewster angle window of diamond material obtained by chemical vapour deposition (CVD) technique has been used in a MW class high power gyrotron. A frequency step-tunable gyrotron has been used for that experiments. Although after brazing the stress profile of the elliptic geometry of the Brewster angle window is more critical than a standard circular geometry the maximum thermal stress is still well below the ultimate strength. A gyrotron operation in the short-pulse regime without additional cooling of the window unit has been achieved. The high power experiments using the frequency step-tunable gyrotron showed an excellent agreement of the output beam with the simulations for several cavity modes in the frequency range from $111.6 \mathrm{GHz}$ up to $165.7 \mathrm{GHz}$. Those promising results will be the base for the future design of a Brewster window for long pulse operation including an appropriate cooling technique.

\section{REFERENCES}

[1] H. Zohm, M. Thumm, "On the use of step-tuneable gyrotrons in ITER", Journal of Physics: Conference Series, 25, 274-282, 2005.

[2] X. Yang, G. Dammertz, R. Heidinger, K. Koppenburg, F. Leuterer, A. Meier, B. Piosczyk, D. Wagner, M. Thumm, "Design of an ultra-broadband single-disk output window for a frequency step-tunable 1 MW gyrotron”, Fusion Eng. and Design, 74, 489-493, 2005.

[3] G.G. Denisov, A.G. Litvak, V.E. Myasnikov, E.M. Tai, V.E. Zapevalov, "Development in Russia of high-power gyrotrons for fusion," Nucl. Fusion, 48, 054007, 2008.

[4] K. Sakamoto, A. Kasugai, K. Kajiwara, K. Takahashi, Y. Oda, K. Hayashi, N. Kobayashi, "Progress of high power 
$170 \mathrm{GHz}$ gyrotron in JAEA", Nucl. Fusion, 49, 095019, 2009.

[5] K.E. Kreischer, R.J. Temkin, "Single-mode operation of a high-power, step-tunable gyrotron”, Phys. Rev. Letters, 59, 547-550, 1987.

[6] M. Thumm, A. Arnold, R. Heidinger, M. Rohde, R. Schwab, R. Spoerl, "Status report on CVD-diamond window development for high power ECRH", Fusion Engineering and Design, 53, 517-524, 2001.

[7] M. Thumm, "MPACVD-diamond windows for highpower and long-pulse millimeter wave transmission", Diamond and Related Materials, 10, 1692-1699, 2001.

[8] R. Heidinger, I. Danilov, A. Meier, B. Piosczyk, P. Späh, M. Thumm, W. Bongers, M. Graswinckel, M. Henderson, F. Leuterer, A.G.A. Verhoeven, D. Wagner, "Development of high power window prototypes for ECH\&CD launchers", Fusion Engineering and Design, 82, 693-699, 2007.

[9] A.G. Litvak, G.G. Denisov, V.E. Myasnikov, E.M. Tai, E.V. Sokolov, V .I. Ilin, "Recent development results in Russia of megawatt power gyrotrons for plasma fusion installations", EPJ Web of Conferences, 32, 04003, 2012.

[10] O. Braz, G. Dammertz, M. Kuntze, M. Thumm, "D-band frequency step-tuning of a $1 \mathrm{MW}$ gyrotron using a Brewster output window", Int. J. Infrared and Millimeter Waves, 18, 1465-1477, 1997.

[11] G. Dammertz, O. Braz, A.K. Chopra, K. Koppenburg, M. Kuntze, B. Piosczyk, M. Thumm, "Recent results of the 1 MW, $140 \mathrm{GHz}, \mathrm{TE}_{22,6}$-mode gyrotron”, IEEE Trans. on Plasma Science, 27, 330-339, 1999.

[12] K. Koppenburg, G. Dammertz, M. Kuntze, B. Piosczyk, M. Thumm, "Fast frequency-step-tunable high-power gyrotron with hybrid-magnet-system", IEEE Trans. on Electron Devices, 48, 101-107, 2001.

[13] E. Borie, O. Drumm, S. Illy, K. Koppenburg, M.V. Kartikeyan, B. Piosczyk, D. Wagner, X. Yang, G. Dammertz, M.K. Thumm, "Possibilities for multifrequency operation of a gyrotron at FZK", IEEE Trans. on Plasma Science, 30, 828-834, 2002.

[14] G. Gantenbein, G. Dammertz, J. Flamm, S. Illy, S. Kern, G. Latsas, B. Piosczyk, T. Rzesnicki, A. Samartsev, A. Schlaich, M. Thumm, I. Tigelis, "Experimental Investigations and Analysis of Parasitic RF Oscillations in High-Power Gyrotrons”, IEEE Trans. on Plasma Science, 38, 1168-1177, 2010.

[15] V.K. Lygin, B. Piosczyk, G. Dammertz, A.N. Kuftin, V.E. Zapevalov, "A diode electron gun for a 1 MW 140 GHz gyrotron”, Int. J. Electronics, 82, 193-201, 1997.

[16] M. Thumm, "State of the Art of High Power GyroDevices and Free Electron Masers”, KIT Scientific Reports 7575, Update 2010.

[17] M. Losert, J. Jin, T. Rzesnicki, "RF Beam Parameter Measurements of Quasi-Optical Mode Converters in the $\mathrm{mW}$ Range”, IEEE Trans. on Plasma Science, 41, 628-632, 2013.

[18] A. V. Chirkov, "Analysis and synthesis of the structure of the field in high-power microwave beams", Radiophys. and Quantum Electronics, 50, 209-215, 2007.

[19] O. Prinz, A. Arnold, G. Gantenbein, Y. Liu, M. Thumm, D. Wagner, "Highly efficient quasi-optical mode converter for a multifrequency high-power gyrotron", IEEE Transactions on Electron Devices, 56, 828-834, 2009.

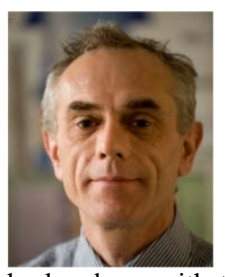

Gerd Gantenbein received the Dipl. Phys. degree in physics and the Dr.-Ing. degree in electrical engineering from the University of Karlsruhe, Karlsruhe, Germany in 1988 and 1993, respectively. In 1988, he joined the Research Center Karlsruhe where he was involved in the development of high power gyrotrons. His research interests included numerical simulation and experimental optimization of gyrotron oscillators. From 1993 to 2005, he has been with the Institute of Plasma Research, University of Stuttgart, Stuttgart, Germany, where he was working on the development of transmission systems for high power radiation. He was also involved in studies and experiments on the interaction of microwaves in magnetically confined plasmas for nuclear fusion applications, especially suppression and stabilization of so-called neoclassical tearing modes. Since 2005 he is with the Institute for Pulsed Power and Microwave Technology of the Research Center Karlsruhe (KIT/FZK) where he is acting as head of the division High Power Microwave Technology. His current research projects are the development of high power gyrotrons, frequency step-tunable gyrotrons and multi-megawatt gyrotrons for electron-cyclotron resonance heating and current drive systems in fusion plasmas.

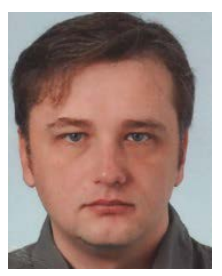

Andrey Samartsev received the Dipl.-Ing. degree in physics from the Technical University of Tashkent, Tashkent, Uzbekistan, in 1996, and the Dr. rer. nat. degree from the University of Essen, Essen, Germany, in 2004. The topics of the study were devoted to the processes at the near surface region of solid state (sputtering, electron emission processes) and development of a continuous wave operation polyatomic ion source. Since 2008 he has joined the Institut für Hochleistungsimpuls- und Mikrowellentechnik (IHM), Forschungszentrum Karlsruhe (FZK, KIT since 2009), Karlsruhe, Germany. Dr. Samartsev is now involved in the development of high-power gyrotrons.

G. Dammertz, photograph and biography not available at the time of publication.

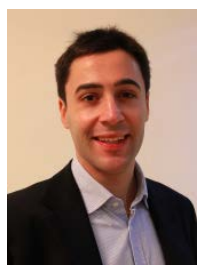

Gaetano Aiello was born in Palermo, Italy, in 1984. He received the M.Sc. degree in safety and nuclear technologies engineering from the University of Palermo in 2008. From 2008 to 2011, he was a trainee for the EFDA goal oriented training programme named ITER Port-Plug Engineering at Karlsruhe Institute of Technology (KIT). He worked on outgassing measurements, design and analysis of components for the ITER EC H\&CD Upper Launcher. Since 2011, he has been working at KIT on numerical analyses for the ITER Upper Launcher and other fusion reactor components, mainly on CFD, thermal, structural and seismic analyses using the ANSYS code.

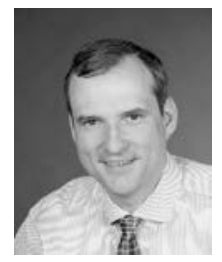

John Jelonnek (M’97) was born in Hamburg, Germany, on April 7, 1965. He received the Dipl.-Ing. and Dr.-Ing. degrees in electrical engineering from Hamburg University of Technology (TUHH), Hamburg, Germany, in 1992 and 2000, respectively.

From 1997 to 2011, John Jelonnek was working in several different positions in industry, including RF research and development, technology and business management. Since 2011, John Jelonnek is the Director of the Institute for Pulsed Power and Microwave Technology (IHM) at the Karlsruhe Institute of Technology (KIT), Karlsruhe, Germany. John Jelonnek is a Professor for high-power microwave technologies at KIT.

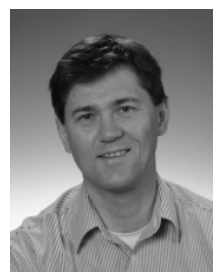

Markus Losert was born in Bretten, Germany on June 15, 1967. He received Dipl.-Ing. degree in the electrical engineering from Universität Karlsruhe in 1995. After working in the Telecom Industry, he joined Forschungszentrum Karlsruhe (FZK), Germany in 2009. His fields of activity are low power tests of quasi optical components for use in gyrotrons and the development of microwave test systems. 


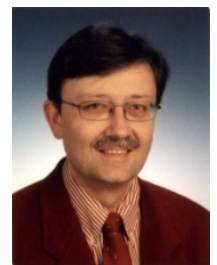

Theo Andreas Scherer was born in Ottweiler/Germany, on January 21, 1962. He received the diploma degree in physics from the University of Karlsruhe/Germany, in 1986 in the fields of plasma physics and solid state physics and electronics. In 1986, he was in the electrotechnical department (IEGI) of the University of Karlsruhe and worked in the field of superconducting electronic, thin film plasma deposition technology and high frequency superconducting electronics. He performed his Ph.D in crystallography of perovskitic systems in high temperature superconductors in 1993 and his D.Sc. in process technology of superconducting electronic circuits in 2001. From 2004 until 2006 he went to the Institute of millimetre wave radio astronomy (IRAM) in Grenoble/France for developing of Hot-Electron-Bolometer-Mixers (HEBs) for space and astrophysics applications. During this time, he was guest scientist on the European Synchrotron Facility (E.S.R.F.) in Grenoble and in the Havards Smithsonian Astrophysics Institute in Cambridge/Boston (U.S.A.). After that time, he went to the Karlsruhe Institute of Technology (KIT) in the Institute for Applied Materials (IAM-AWP) as deputy project leader for the ITER ECRH Upper Launcher and for the development of diamond window technology for high power microwave transmission in gyrotrons and fusion reactors. He is also associate professor in KIT.

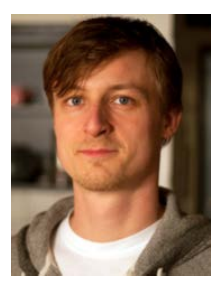

Andreas Schlaich was born in Freudenstadt, Germany, in 1982. After his studies at the University of Karlsruhe (Karlsruhe Institute of Technology (KIT) since 2009) he received the Dipl.-Ing. degree in electrical engineering and information technology with a focus on microwave technologies in 2009.

Since 2010, he has worked as a doctoral student in the framework of a collaboration between the Institute for Pulsed Power and Microwave Technology (IHM) and the Institut für Hochfrequenztechnik und Elektronik (IHE) of KIT in Karlsruhe, Germany.

His work is concerned with the improvement of millimeter-wave diagnostics and the investigation of dynamic processes in high power gyrotrons.

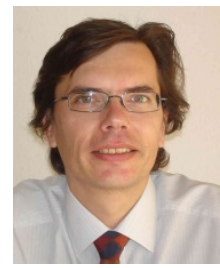

Dirk Strauss obtained his degree in physics at the University of Heidelberg. During his $\mathrm{PhD}$ he investigated on corrosion optimization techniques for high temperature gas turbine coatings with the use of pulsed electron beams. In 2006 he joined KIT in Karlsruhe, Germany, and contributed to the ITER project on the areas diamond windows and design validation. Since its implementation in 2011 he leads the European Electron Cyclotron Heating Upper Launcher Consortium of Associations ECHUL-CA. In parallel he is working on new ECH technologies beyond ITER including broadband diamond window developments.

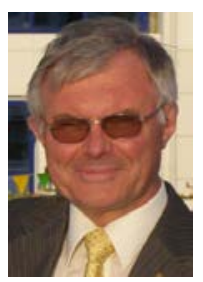

Manfred Thumm (SM'94-F'02) was born in Magdeburg, Germany, on August 5, 1943. He received the Dipl. Phys. and Dr. rer. nat. degrees in physics from University of Tübingen, Germany, in 1972 and 1976, respectively.

At the University of Tübingen he was involved in the investigation of spin-dependent nuclear forces in inelastic neutron scattering. From 1972 to 1975 he was Doctoral Fellow of the Studienstiftung des deutschen Volkes. In 1976 he joined the Institute for Plasma Research in the Electrical Engineering Department of the University of Stuttgart, Germany, where he worked on RF production and RF heating of toroidal pinch plasmas for thermonuclear fusion research. From 1982 to 1990 his research activities were mainly devoted to electromagnetic theory and experimental verification in the areas of component development transmission of very high power millimeter waves through overmoded waveguides and of antenna structures for RF plasma heating with microwaves. In June 1990 he became a Full Professor at the Institute for Microwaves and Electronics of the University of Karlsruhe, Germany, and Head of the Gyrotron Development and Microwave Technology Division, Institute for Technical Physics, Research Center Karlsruhe (Forschungszentrum Karlsruhe: FZK). From April 1999 to September 2011, he was the Director of the Institute for Pulsed Power and Microwave Technology, FZK, where his current research projects have been the development of high power gyrotrons, dielectric vacuum windows, transmission lines and antennas for nuclear fusion plasma heating, and industrial material processing. On October 1, 2009, the University of Karlsruhe and the FZK have merged to the Karlsruhe Institute of Technology (KIT). M. Thumm has authored/co-authored 6 books, 20 book chapters, 303 research papers in scientific journals, and more than 1290 conference proceedings articles. He holds 12 patents on active and passive microwave devices.

He is member of the IEEE EDS Vacuum Devices Technical Committee and the NPSS PSAC Executive Committee, a member of the Chapter 8.6 Committee Vacuum Electronics and Displays of the Information Technical Society in German VDE (Chairman from 1996 to 1999) and a member of the German Physical Society. From 2007 to 2008 he was the vice chairman of the Scientific-Technical Council of FZK and of the Founding Senate of KIT. From 2008 to 2010 he was the deputy head of the Topic Fusion Technology of KIT Energy. He was the General Chair of the IRMMW-THz 2004 and IEEE ICOPS 2008 Conferences in Karlsruhe, Germany. He has been a member of the International Organization and Advisory Committees of many International Conferences and a member of the Editorial Boards of several ISI refereed journals. From 2003 to 2010 he was ombudsman for upholding good scientific practice at FZK/KIT. Since 2012 he has been Associate Editor for Vacuum Electronics Devices for IEEE Trans. Electron Devices and Distinguished Lecturer of IEEE NPSS and since 2013 Distinguished Scientist of KIT and member of the International Advisory Committee of Cooperative Innovation Centre of $\mathrm{THz}$ Science in China.

In 2000 he was awarded with the Kenneth John Button Medal and Prize and in 2002 with the title of Honorary Doctor, presented by the St. Petersburg State Technical University. He received the IEEE-EDS 2008 IVEC Award for Excellence in Vacuum Electronics. Together with two of his colleagues he received the 2006 Best Paper Award of the Journal of Microwave Power and Electromagnetic Energy and the 2009 CST University Publication Award. In 2010 he was awarded with the IEEE-NPSS Plasma Science and Applications Award. He was a winner of the 2010 open grant competition of the Government of the Russian Federation to support scientific research projects implemented under supervision of Leading Scientists at Russian institutions of higher education. Together with A. Litvak and K. Sakamoto he has been the recipient of the Plasma Physics Innovation Prize 2011 of the European Physical Society (EPS). In 2012 he was awarded with the Heinrich Hertz Prize of the EnBW Foundation and the KIT and the HECTOR School Teaching Award in Embedded Systems Engineering.

D. Wagner, photograph and biography not available at the time of publication. 